\title{
Analysis of Lubrication Performance of Thrust Bearing with Texture Height Variation and Cavitation Modelling with CFD Simulation
}

\author{
M Muchammad ${ }^{1, *}$ M Tauviqirrahman ${ }^{1} \mathrm{H}$ Nurahman ${ }^{1} \mathrm{~J} \mathrm{Jamari}^{1}$
}

\author{
${ }^{1}$ Laboratory for Engineering Design and Tribology, Mechanical Engineering Department, Diponegoro University, \\ Indonesia \\ *Corresponding author.Email: mmad5373@yahoo.com
}

\begin{abstract}
Increased load support performance can be achieved by adding texture on the bearing surfaces. A study on the high textured effect on the hydrodynamic thrust bearing by cavitation is presented in this paper. The textured surface is applied in rectangular geometric with several dimension. The single-textured thrust bearing with several heights was analyzed by numerical methods based on Reynold's equation and 2D CFD model analysis based on Navier-Stokes equation. The result showed that the pressure distribution with higher textured surfaces could increase the load support in hydrodynamic thrust bearings; in other words, the height of the texture will affect thrust bearing performance.
\end{abstract}

Keywords: Lubrication Performance, Bearing, CFD Simulation.

\section{INTRODUCTION}

The use of bearings can be seen as support on the shaft so that it can rotate adequately. Generally, bearings are used in electric motor systems and turbomachinery engines. There are two types of covers, contact and contactless. In non-contact bearings the mechanical elements such as sliding and rolling are replaced by a thin layer (film) which contains pressurized fluid as load support, this type of bearing is also known as a hydrodynamic bearing where the load capacity will depend on the area, speed, and viscosity of the lubricant [1].

Texture surface on thrust bearing is applied by profiling in a well-defined geometric form such as a dimple or groove; this is different from roughness which has a random geometric characteristic. Texture also has an impact on bearing performance, where micro irregularities on the surface of the rotating shaft can generate hydrodynamic pressure to construct load support, therefore giving texture is a feasible method for improving bearing performance, one of them is in terms of capacity for load carriers [2].

The texture effect on thrust bearing performance has been studied for a long time; where texturing with dimple geometry can significantly increase load support at high speeds, this can be explained when heat dissipation in load area is to be better because circulation for the fluid becomes more efficient [3].

As for research about the effect of height of texture and velocity on textured thrust bearings by comparing the analytical method using the Reynolds equation and CFD simulation analysis using the Navier-Stokes equation, in this study, It shows that the texture ratio is one of the factors that affects the precision of the Reynolds equation, and it is concluded that the equation Reynolds can be applied to high texture and low Reynolds number thrust bearings [4]. Besides, based on the theoretical analysis, it is known that using vary texture and velocity on thrust bearings can generate different cavitation area [5]. The research focused on the effect of the height of texture on the performance of thrust bearings with cavitation modeling in mind, with a numerical approach analysis method through Reynolds equation and CFD analysis.

\section{METHOD}

\subsection{Theory}

In this study, Continuity and Navier-Stokes equations, which control CFD equations, are used for incompressible fluid analysis and expressed as follows. [6]. 
$\nabla \cdot v^{\prime}=0$

$\rho \frac{D \vec{v}}{D t}=-\nabla p+\mu \nabla^{2} \cdot \vec{v}+S_{M}$

Where $v_{\text {in }}$ the cartesian coordinates is the speed, $S_{M}$ is an influence on the fluid flow; $\mu$ is fluid viscosity; $p$ is fluid density; $p$ is fluid pressure.

In this study, cavitation modelling was used Schnerr and Sauer [7]. Turbulent conditions need to be considered because that was a parameter which is difficult to avoid when the bearing works. The turbulent model used in this study RNG $k-\sum$ model that systematically removes smaller motion levels from the governing equations in terms of greater movement and modified viscosity. RNG $k$ - $\sum$ model equation is expressed as follows [6].

$$
\begin{aligned}
& \frac{\partial(\rho k)}{\partial t}+\nabla \cdot(\rho k \mathbf{U})=\nabla \cdot\left[\alpha_{k} \mu_{e f f} \nabla k\right]+2 \mu_{t} E_{i j} \cdot E_{i j}-\rho \varepsilon \\
& \frac{\partial(\rho \varepsilon)}{\partial t}+\nabla \cdot(\rho \varepsilon \mathbf{U})=\nabla \cdot\left[\alpha_{\varepsilon} \mu_{e f f} \nabla \varepsilon\right]+C_{1 \varepsilon}^{*} \frac{\varepsilon}{k} 2 \mu_{t} E_{i j} \cdot E_{i j}-C_{2 \varepsilon} \rho \frac{\varepsilon^{2}}{k}
\end{aligned}
$$

$\quad \mu_{e f f}=\mu+\mu_{t} ; \quad \mu_{t}=\rho C_{\mu} \frac{k^{2}}{\varepsilon}$,with
where
$C_{\mu}=0.0845 ; \alpha_{k}=\alpha_{\varepsilon}=1.39 ; C_{1 \varepsilon}=1.42 ; C_{2 \varepsilon}=1.68$

and

$C_{1 \varepsilon}^{*}=C_{1 \varepsilon}-\frac{\eta\left(1-\eta / \eta_{0}\right)}{1+\beta \eta^{3}} ; \quad \eta=\left(2 E_{i j} \cdot E_{i j}\right)^{1 / 2} \frac{k}{\varepsilon} ; \quad \eta_{0}=4.377 ; \beta=0.012$.

\subsection{CFD Model}

Thrust bearing geometry used in this study considering cavitation condition and several texture dimension. Thrust bearing geometry can be seen in Figure 1, for the specification of thrust bearing can be found in Table 1, and fluid properties are shown in Table 2.

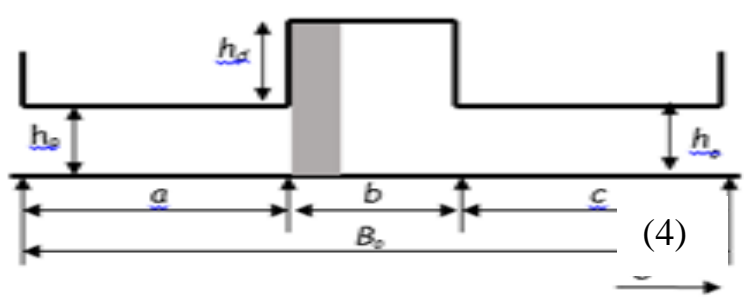

Figure $12 \mathrm{D}$ geometry of thrust bearing model

Table 1. Main parameters of single-textured bearing characteristics.

\begin{tabular}{llll}
\hline Parameter & Symbol & Value & Unit \\
\hline Bearing Length & $B_{o}$ & 2 & $\mathrm{~mm}$ \\
Inlet length & $a$ & 0.2 & $\mathrm{~mm}$ \\
Texture length & $b$ & 0.15 & $\mathrm{~mm}$ \\
Outlet length & $c$ & 0.165 & $\mathrm{~mm}$ \\
Minimum thickness of film & $h_{o}$ & 1 & $\mu \mathrm{m}$ \\
Texture depth & $h_{d}$ & $0.75 ; 1 ; 1.25$ & $\mu \mathrm{m}$ \\
Pressure inlet & $P_{a}$ & 100 & $\mathrm{kPa}$ \\
Pressure of cavitation & $P_{c}$ & 100 & $\mathrm{kPa}$ \\
Sliding speed & $U$ & 1 & $\mathrm{~m} / \mathrm{s}$ \\
\hline
\end{tabular}

Table 2. Lubricant properties

\begin{tabular}{lllll}
\hline Parameter & Symbol & Oil & Oil Vapor & Unit \\
\hline Density & $\rho$ & 962 & 0.02556 & $\mathrm{~kg} / \mathrm{m}^{3}$ \\
Viscosity & $\mu$ & 0.013468 & $1.256 \times 10^{-5}$ & Pa-s \\
\hline
\end{tabular}

The computer grid has been constructed with a quadrilateral mesh type. The grid at the texture edges is tighter to ensure accurate analysis of the texture. The number of grids in single-text geometry and longitudinal $(\mathrm{Nx})$ and cross $(\mathrm{Nz})$ directions in Figure 2 shows 1000x35 with 14,446 and cells as well as 15,100 nodes.

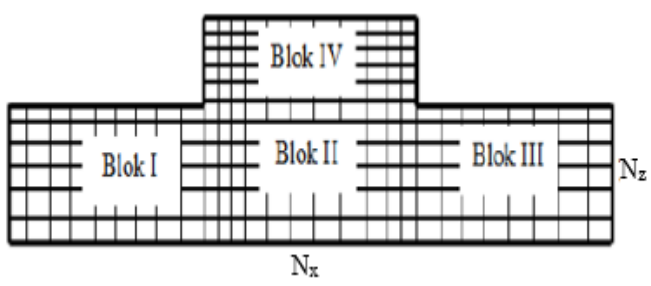

Figure 2 Illustration of the thrust bearing computer grid 


\section{RESULT AND DISCUSSION}

The research was conducted by comparing the results of pressure distribution on thrust bearing based on Reynolds equation and Navier-Stokes equation with an error $<10 \%$, thrust bearing performance can be observed by pressure distribution and load support on each

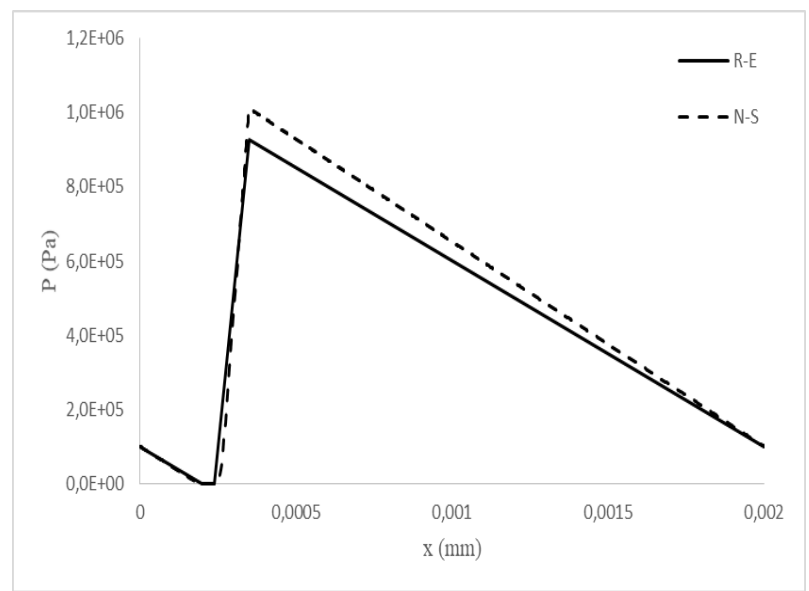

(a) geometry. Based on results, it is known the highestpressure distribution is at the height $H_{d}=1 \mu \mathrm{m}$ with $P_{\max }$ $=1.015 \mathrm{Mpa}$. The highest load support is obtained at the height $H_{d}=1.25 \mu \mathrm{m}$ with $W=988.43 \mathrm{~N}$. The figure of pressure distribution for each thrust bearing can be seen in Figure 3, and the figure of pressure distribution and load support is shown in Figure 4 and Figure 5.

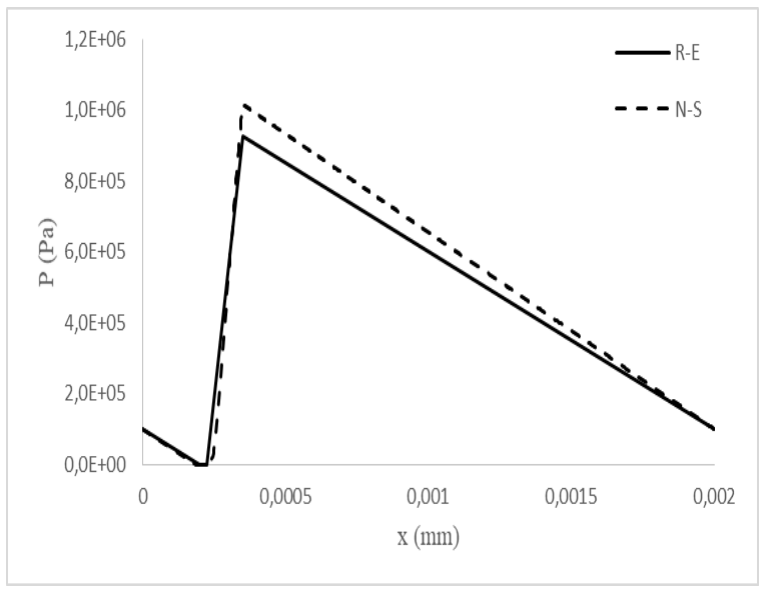

(b)

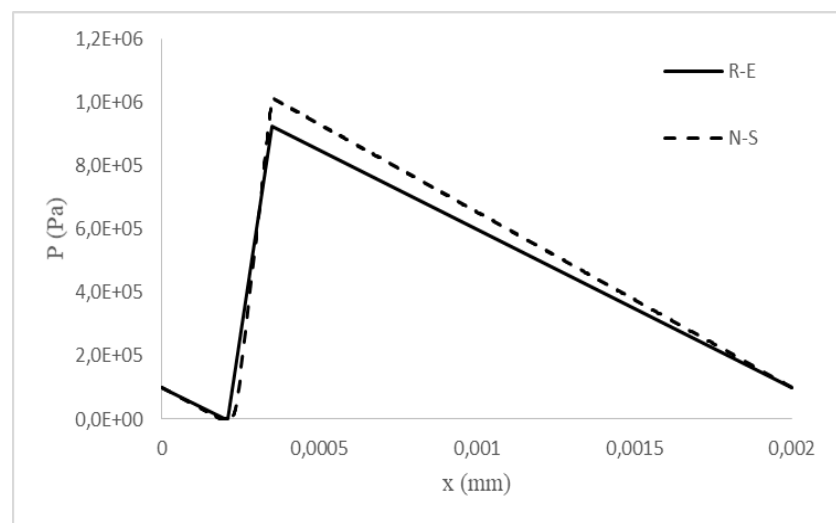

(c)

Figure 3 Pressure distribution on the thrust bearing at (a) $\mathrm{Hd}=0.75 \mu \mathrm{m}$ (b) $\mathrm{Hd}=1 \mu \mathrm{m}$ and (c) $\mathrm{Hd}=2 \mu \mathrm{m}$.

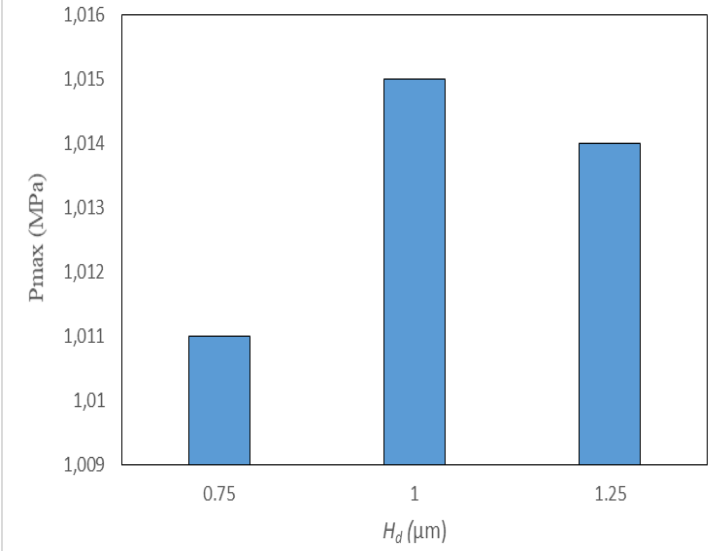

Figure 4 Pressure distribution on the thrust bearing with the variation of texture height.

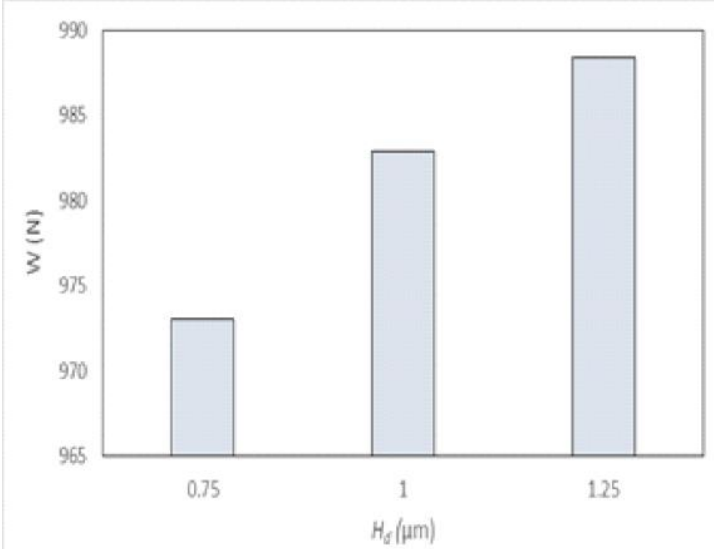

Figure 5 Load support on thrust bearing with the variation of texture height. 


\section{CONCLuSION}

The conclusions are summarized as follows based on an analysis of the texture's effect height:

1. Texture height makes it possible to change the thrust bearing pressure distribution.

2. With increasing texture height, load support has increased.

\section{REFERENCES}

[1] Slocum A, 2008 Fundamentals of Design and Specification

[2] Gropper D, Wang L, Harvey T J, 2015 Hydrodynamic lubrication of textured surfaces: A review of modeling techniques and key findings Tribology International 94 509-529
[3] Snegovskii F P, Bulyuk N G, 1983 Study of Lubrication of Sliding Bearings with Microgrooves on the Shafts Treniei Iznos 4(2) 322-329

[4] Dobrica M B, Fillon M, 2009 About the validity of Reynolds equation and inertia effects in textured sliders of infinite width Proceedings of the Institution of Mechanical Engineers, Part J: Journal of Engineering Tribology 223(1) 69-78

[5] Muchammad M, Hilmy F, Tauviqirrahman M, Jamari J, Schipper D J, 2018 CFD analysis of texture depth effect on the performance of hydrodynamic lubricated bearing Journal of Physics: Conference Series 1090

[6] Versteeg H K, Malalasekera W 1995 An Introduction to Computational Fluid Dynamics The Finite Volume Method, 1st ed. Essex: Longman Scientific \& Technical.

[7] ANSYS, Inc. 2009 ANSYS FLUENT 12.0 Theory Guide 